\title{
Design of a Variable-Conductance Vacuum Insulation
}

D. K. Benson, T. F. Potter, C. E. Tracy Presented at the SAE 1994 Annual Meeting February 28 - March 3, 1994 Detroit, Michigan

National Renewable Energy Laboratory 1617 Cole Boulevard Golden, Colorado 80401-3393 A national laboratory operated for the U.S. Department of Energy under contract No. DE-AC02-83CH10093

Prepared under Task No. WU230003 


\section{NOTICE}

NOTICE: This report was prepared as an account of work sponsored by an agency of the United States government. Neither the United States government nor any agency thereof, nor any of their employees, makes any warranty, express or implied, or assumes any legal liability or responsibility for the accuracy, completeness, or usefulness of any information, apparatus, product, or process disclosed, or represents that its use would not infringe privately owned rights. Reference herein to any specific commercial product, process, or service by trade name, trademark, manufacturer, or otherwise does not necessarily constitute or imply its endorsement, recommendation, or favoring by the United States govemment or any agency thereof. The views and opinions of authors expressed herein do not necessarily state or reflect those of the United States government or any agency thereof.

Printed in the United States of America

Available from:

National Technical Information Service

U.S. Department of Commerce

5285 Port Royal Road

Springfield, VA 22161

Price: Microfiche $\mathrm{AO1}$

Printed Copy $\mathrm{AO2}$

Codes are used for pricing all publications. The code is determined by the number of pages in the publication. Information pertaining to the pricing codes can be found in the current issue of the following publications which are generally available in most ibraries: Energy Research Abstracts (ERA); Government Reports Announcements and Index (GRA and I); Scientific and Technical Abstract Reports (STAR); and publication NTIS-PR-360 available from NTIS at the above address. 


\title{
Design of a Variable-Conductance Vacuum Insulation
}

\author{
David K. Benson \\ Thomas F. Potter \\ C. Edwin Tracy \\ National Renewable Energy Laboratory \\ Golden, CO 80401
}

\section{ABSTRACT}

This paper describes one approach to the design of a variable-conductance vacuum insulation. In this design, the vacuum insulation consists of a permanently sealed, thin sheet steel, evacuated envelope of whatever geometry is required for the application. The steel envelope is supported internally against the atmospheric pressure loads by an array of discrete, low-conductance, ceramic supports, and radiative heat transfer is blocked by layers of thin metal radiation shields. Thermal conductance through this insulation is controlled electronically by changing the temperature of a small metal hydride connected to the vacuum envelope. The hydride reversibly absorbs/desorbs hydrogen to produce a hydrogen pressure typically within the range from less than $10^{-6}$ to as much as 1 torr. Design calculations are compared with results from laboratory tests of bench scale samples, and some possible automotive applications for this variableconductance vacuum insulation are suggested.

\section{INTRODUCTION}

VACUUM INSULATION - Vacuum insulation is commonly used in spherical or cylindrical containers ranging in size from lunch bottles to over-the-road liquified gas transport tankers. In such geometries, the container has sufficient strength to support the atmospheric pressure loads, and it is unnecessary to provide strong internal supports between the inner and outer walls of the evacuated envelope. The evacuated envelope may be completely empty, as in the lunch bottle, or filled with a compacted, multi-layer wrap of thin aluminum foil separated by polymer or glass fiber spacers, as in the liquified gas tank. The vacuum is permanent and the insulation value is fixed.

But what if the insulated container surrounds a system which must be insulated part of the time and must reject or absorb heat from the-outside at other times? Usually, such an application would require a heat exchange loop to pass through the container. Such a loop would add heat loss paths through the container, com- promising its insulating performance and complicating the system design.

VARIABLE-CONDUCTANCE VACUUM INSULATION - Variable-conductance vacuum insulation is a form of evacuated thermal insulation which can be made conductive by introducing low-pressure hydrogen gas. The pressure of hydrogen is electrically controlled by heating a small container of metal hydride such as zirconium hydride. Such hydrides produce thermodynamically determined, equilibrium hydrogen pressures that are a predictable function of the hydride temperature.

Hydrogen gas has a very high thermal conductivity, even at pressures of less than $10^{-5} \mathrm{~atm}$, so that a very small amount of hydrogen is sufficient to fill a large vacuum-insulation enclosure and make it thermally conductive. When the hydride is allowed to cool, it will quickly reabsorb the hydrogen, reestablishing the vacuum and restoring the thermal resistance of the insulation. Control of the thermal conductance is continuously adjustable by controlling the hydride temperature.

This paper describes some of the design considerations for a variable-conductance insulation ( $\mathrm{VCl}$ ) and suggests some possible applications in the automotive industry. Topics covered include the thermal conductivity of low pressure hydrogen, the dependence of vacuum insulation thermal conductance upon the pressure of intemal hydrogen gas, the quantity of gas required, characteristics of selected metal hydrides and their required quantity, and remaining problems of manufacturing $\mathrm{VCl}$. The design calculations are compared with test results from a bench-scale $\mathrm{VCl}$ panel.

\section{DESIGN ANALYSIS}

THERMAL CONDUCTIVITY. OF LOW-PRESSURE HYDROGEN GAS - Hydrogen is a low molecular weight, diatomic gas which has a very high thermal conductivity. The elementary, kinetic theory of gas dynamics is adequate to accurately calculate the thermal conductivity of low-pressure hydrogen at temperatures above about $100 \mathrm{~K}$ [1]. At atmospheric pressure, the conductivity of 
hydrogen is $0.173(\mathrm{~W} / \mathrm{mK})$, compared to air at 0.024 and helium at 0.142 [2].

At low pressures, the gas molecules can move uninhibited from a hot surface where they pick up heat energy to a cooler surface where they deposit this energy. Adding more molecules increases the pressure and the amount of thermal power which is conducted between the warm and cool surfaces. Consequently, the thermal power conducted by a gas across an area, A, at low pressure is proportional to the pressure:

$$
\text { Power }_{L P}=\mathrm{P} * \alpha * \kappa *\left(\mathrm{~T}_{\text {hot }}-\mathrm{T}_{\text {cold }}\right) * \frac{\mathrm{A}}{\mathrm{Z}}
$$

where $Z$ is the thickness of the gas-filled gap and

$$
\alpha=\left(\alpha_{1} \alpha_{2}\right) /\left(\alpha_{1}+\alpha_{2}-\alpha_{1} \alpha_{2}\right)
$$

is a measure of the efficiency with which the gas molecules exchange energy with the solid surfaces. The $\alpha_{1}$ and $\alpha_{2}$ are called accommodation coefficients for the gas on the surfaces number 1 and number 2 , where

$$
\alpha_{i}=\left(T_{r}-T_{0}\right) /\left(T_{i}-T_{0}\right)
$$

Their values can range from 0 to 1 but most commonly are between 0.25 and 0.33 for hydrogen on clean surfaces [3]. $\kappa$ is the mean free-molecular heat conductivity of the gas:

$$
\kappa=\frac{1}{8}[(\gamma+1) /(\gamma-1)] * \frac{v}{T_{\text {hot }}}
$$

where $\gamma$ is the ratio of specific heats $C_{p} / C_{v}$ and $v$ is the molecular velocity:

$$
v=(8 \mathrm{kT} / \pi \mathrm{m})^{1 / 2}
$$

At higher pressures, the movement of the gas molecules is impeded by collisions with one another, and the addition of more molecules per unit volume (increased pressure) no longer increases the conductivity, which becomes limited by the viscosity of the gas:

$$
\text { Power }_{\text {HP }}=1 / 4(9 \gamma-5) * \eta * C_{v} *\left(T_{\text {hot }}-T_{\text {cold }}\right) * \frac{A}{Z}
$$

where $\eta$ is the gas viscosity

$$
\eta=\left(0.499(4 \mathrm{mkT})^{1 / 2}\right) /\left(\pi^{3 / 2} \mathrm{~d}_{0}^{2}\right)
$$

$\mathrm{C}_{v}$ is the specific heat of the gas at constant volume, and $\gamma$ is the ratio of specific heats $C_{p} / C_{v}=1.4$ for simple diatomic gases such as hydrogen. The effective diameter of the molecule, $d_{o}$, determines the extent to which molecules collide and naturally influences the gas viscosity (above) and the mean-free distance between collisions (the mean-free path length) described below. where $n_{c}$ is the gas density in number of molecules per unit volume and is related to the gas pressure through

$$
m f p=\left(\pi d_{0}^{2} n_{c} \sqrt{2}\right)^{-1}
$$

the ideal gas law:

$$
n_{c}=N_{A} P_{c} / R T
$$

where $R$ is the universal gas constant. The pressure at which the transition occurs between pressure-dependent and pressure independent thermal conductivity is the pressure at which the mean-free path becomes comparable to the distance between the hot and cold surfaces. In this transition pressure regime, the total gasphase conductivity is a combination of the two processes and may be calculated by adding the two kinds of gasphase thermal resistances processes in parallel [4]:

$$
\text { Power }=\left(1 / \text { Power }_{L P}+1 / \text { Power }_{H P}\right)^{-1}
$$

The conductance through a thickness of gas is equal to the gas thermal conductivity divided by the thickness. Figure 1 shows the calculated thermal conductance of hydrogen gas across a. $20 \mathrm{~mm}$ gap as a function of pressure. Notice that the pressure-dependent change in thermal conductance occurs over a limited range of pressures. The transition between pressure-dependent and pressure independent conductance begins at about $10^{-2}$ torr, where the $\mathrm{mfp}$ is about $10 \mathrm{~mm}$.

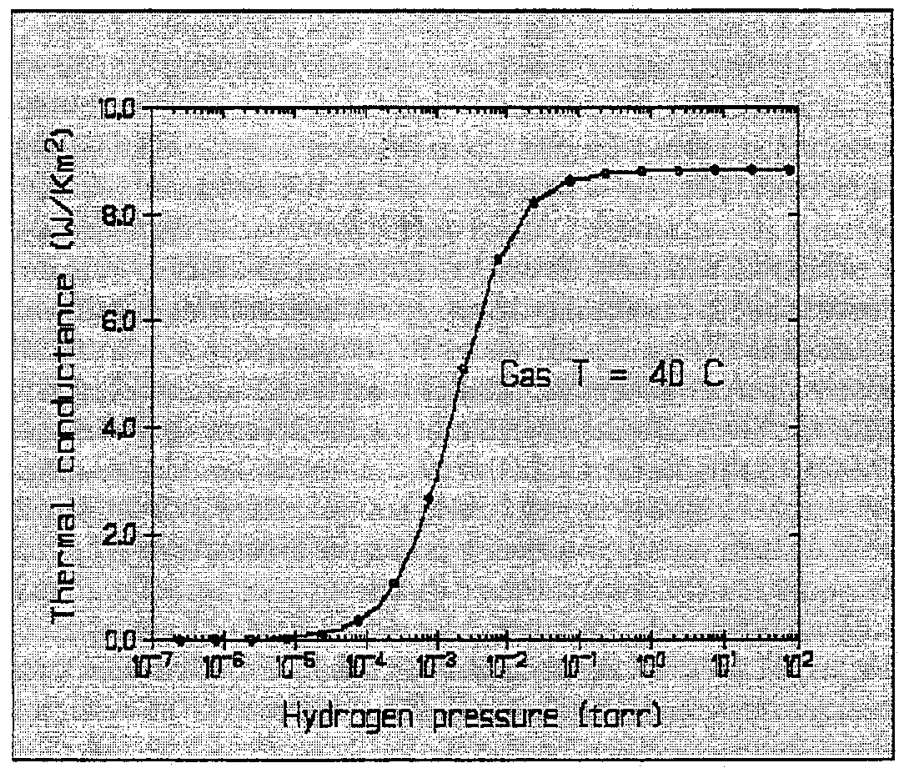

Figure 1. Calculated thermal conductance through the $20 \mathrm{~mm}$ thickness of a $\mathrm{VCl}$ panel as a function of internal hydrogen pressure.

\section{QUANTITY OF HYDROGEN REQUIRED -} Combining EQs (8) and (9) gives the critical hydrogen pressure, above which little change in thermal conductance occurs:

$$
P_{c} \approx R T /\left(10 Z \pi d_{0}^{2} N_{A} \sqrt{2}\right)
$$

The total amount of hydrogen required to reach this pressure (per unit area of $\mathrm{VCl}$ ) is 


$$
M_{H 2}=M W_{H 2} P_{c} Z / R T=\frac{M W_{H 2}}{10 N_{A} d_{0}^{2} \sqrt{2} \pi}
$$

METAL HYDRIDES - A large number of metal hydrides could be considered for use in VCl. Table 1 lists some of these and their characteristics. Zirconium alloys which are used in the manufacture of non-evaporable getters form reversible hydrides with suitable properties and have been used commercially for this purpose. A commercially available alloy used as a hydrogen source is $\mathrm{Zr}-\mathrm{V}-\mathrm{Fe}(.7-.246-.054)$ [6]. This material is used as a fine powder contained within a porous stainless-steel cylinder containing a ceramic insulated, tungsten heater coil. The equilibrium pressure of hydrogen over this powder is given by a Sieverts' equation [7].

$$
P_{H 2}=P_{0} x^{2} \exp \left(\frac{-E_{a}}{B T_{a}}\right)
$$

where $P$ is the equilibrium hydrogen pressure, $E_{a}$ is the activation energy, and $T_{a}$ is the hydride operating temperature in Kelvin. The parameters in the Sieverts' equation for this commercial alloy are $P_{0}=1.08^{\star} 10^{9} \mathrm{~Pa}$ and $E_{a}=1.21 \mathrm{eV} /$ atom. Figure 2 shows the equilibrium pressure over similar alloys as a function of hydrogen concentration in the alloy at different temperatures. The hydrogen concentration is expressed as $x$, the atomic fraction of $\mathrm{H}$ in $\mathrm{ZrH}_{\mathrm{x}}$, since the behavior of these alloys follows the $\mathrm{Zr}-\mathrm{H}$ phase diagram and the other alloy components do not play a prominent role in the hydrogen absorption.

Table 1.

\begin{tabular}{|c|c|c|}
\hline $\begin{array}{l}\text { Hydrogen } \\
\text { Source }\end{array}$ & $H\left(10^{28}\right.$ atoms $\left./ \mathrm{m}^{3}\right)$ & $\begin{array}{l}\text { Disassociation } \\
\text { Temperature (C) }\end{array}$ \\
\hline $\mathrm{TiH}_{2}$ & 9.5 & 650 \\
\hline $\mathrm{UH}_{3}$ & 8.2 & 430 \\
\hline $\mathrm{ZrNiH}_{3}$ & 7.4 & 295 \\
\hline $\mathrm{LaNiH}_{6.7}$ & 7.6 & 25 \\
\hline
\end{tabular}

Hydrogen Densities in Hydrogen Sources [5]

QUANTITY OF HYDRIDE - The geometry of the $\mathrm{VCl}$ enclosure dictates the critical pressure, $P_{c}(E Q(11))$, of hydrogen needed to saturate the gas-phase conductance and thereby inactivate the vacuum insulation. For a $\mathrm{VCl}$ with an interior spacing of $3 \mathrm{~mm}$ between the layers of radiation shields, this critical hydrogen pressure is about $10^{-2}$ torr (Fig. 1).

The critical hydrogen pressure can be reached by heating a hydride alloy to a temperature at which it is in thermodynamic equilibrium with hydrogen at that critical pressure (Fig. 2). The larger the initial hydrogen content of the alloy, the lower the temperature required to reach the critical pressure. For a value of $x=0.01$ in the $\mathrm{ZrH}_{\mathrm{x}}$

\section{Hydrogen concentration (torr-l/g)}

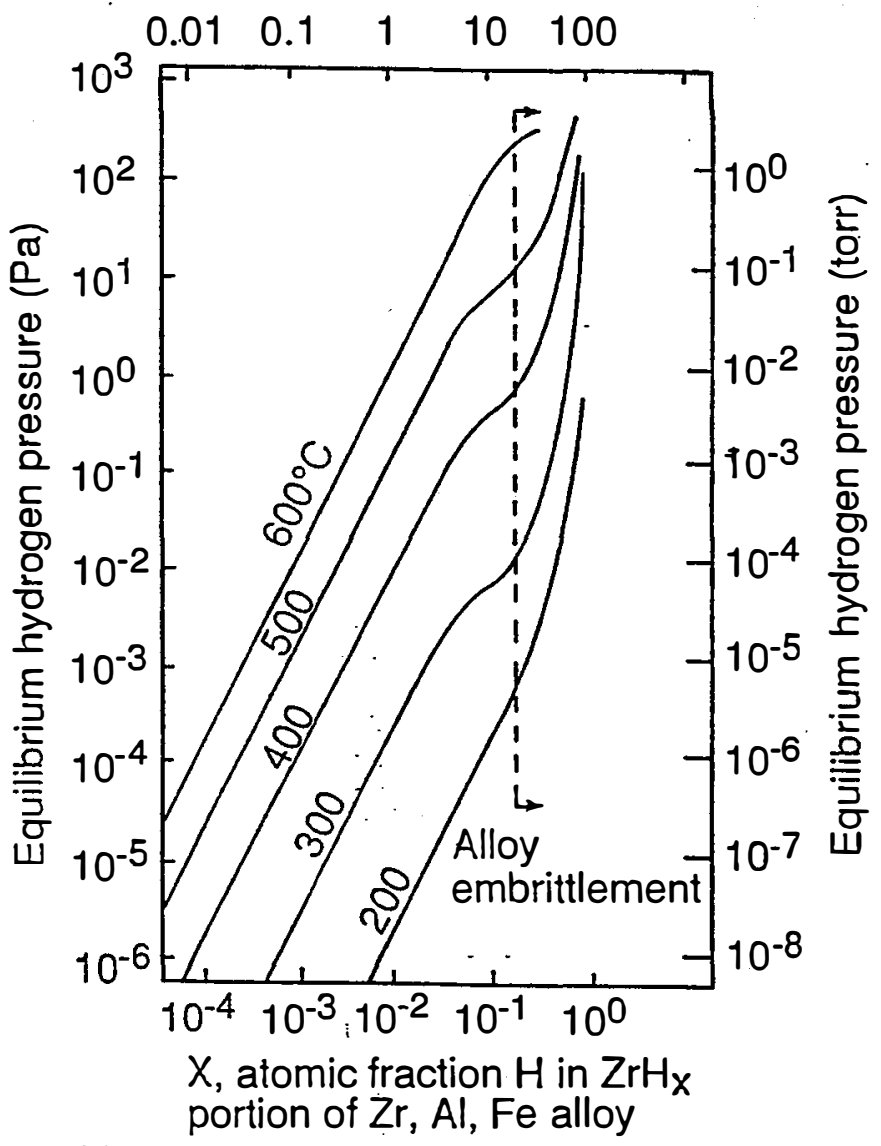

Figure 2. Equilibrium hydrogen pressure over various zirconium alloy hydrides(5).

hydride, the hydride dissociation temperature required is nearly $600^{\circ} \mathrm{C}$, whereas for $x=0.1$, the required dissociation temperature is only about $450^{\circ} \mathrm{C}$.

As the hydrogen is evolved from the hydride, the value of $x$ decreases. Consequently, so does the equilibrium hydrogen pressure which can be sustained by the hydride at the dissociation temperature. Therefore, the value of $x$ must be selected somewhat higher than the required final value at the hydride operating temperature.

Enough hydride must be incorporated into the $\mathrm{VCl}$ to provide the required amount of hydrogen and still leave the fraction of hydrogen, $x$, in the hydride large enough to remain above the critical value associated with the critical hydrogen pressure at the hydride operating temperature. The amount of hydrogen needed is given by $E Q(12)$ in terms of the critical hydrogen pressure and $\mathrm{VCl}$ separation between hot and cold surfaces. The amount of hydrogen may also be expressed in terms of the change in $\mathrm{x}$ in the $\mathrm{ZrH}_{\mathrm{x}}$ portion of the hydride alloy:

$$
M_{\mathrm{H} 2}=\Delta x M_{\mathrm{HY}} \mathrm{F}_{\mathrm{Zr}}\left[\mathrm{MW}_{\mathrm{H} 2} / 2 \mathrm{MW}_{\mathrm{Zr}}\right]
$$


where $\mathrm{F}_{\mathrm{Zr}}$ is the weight fraction of zirconium in the (un-hydrided) alloy and $\left(\mathrm{MW}_{\mathrm{H} 2} / 2 \mathrm{MW}_{\mathrm{Zr}}\right)$ is the ratio of a hydrogen atom weight to a zirconium atom weight expressed in terms of standard molecular weights. Combining this equation with $E Q(12)$ yields an expression for $\Delta \mathrm{x}$ :

$$
\Delta \mathrm{X}=\left(2 \mathrm{P}_{\mathrm{c}} \mathrm{zMW}_{\mathrm{zr}}\right) /\left(\mathrm{RTM}_{\mathrm{HY}} \mathrm{F}_{\mathrm{Zr}}\right)
$$

The final value of $x$ must be large enough to assure a critical hydrogen pressure, $\mathrm{Pc}$, at the hydride operating temperature, $T_{a}$. This value of $x_{\text {final }}$ is obtained from $E Q(13)$ :

$$
x_{\text {final }}=\left[P_{c} /\left(P_{o} \exp \left(-E_{a} / B T_{a}\right)\right)\right]^{1 / 2}
$$

Finally, the initial value of $x$ is dependent upon the amount of hydride alloy to be used as well as the other details of the design, such as the $\mathrm{VCl}$ geometry and the hydride operating temperature:

$$
\begin{aligned}
& x_{\text {initial }}=x_{\text {final }}+\Delta x \\
= & {\left[P_{c} /\left(P_{\circ} \exp \left(-E_{a} / B T_{a}\right)\right)\right]^{1 / 2} } \\
+ & \left(2 P_{c} Z M W_{Z r}\right) /\left(R T M_{H Y} F_{Z r}\right)
\end{aligned}
$$

The amount of hydride alloy (in terms of grams per square meter of $\mathrm{VCl}$ projected surface area) can be expressed in terms of the critical hydrogen pressure and the selected $x_{\text {initial }}$ as:

$$
\text { mhy }=2 \mathrm{P}_{\mathrm{c}} \mathrm{zMW} \mathrm{Zrr}_{\mathrm{zr}} /\left[\mathrm{RTF}_{\mathrm{Zr}}\left(\mathrm{x}_{\mathrm{i}}-\mathrm{P}_{\mathrm{c}} / \mathrm{P}_{\mathrm{H} 2}\right)^{1 / 2}\right]
$$

where $P_{c}$ and $P_{H 2}$ are obtained from EQs (11) and (13), respectively. It is interesting that the amount of hydride is not dependent upon the thickness of the vacuum gap in the $\mathrm{VCl}$. This independence results from the cancellation of two effects: the critical pressure is inversely proportional to the gap thickness, whereas the volume of hydrogen at the critical pressure is directly proportional to the gap thickness.

The $\mathrm{VCl}$ designer can choose to use more or less hydride alloy depending on how high an operating temperature he chooses for the hydride and how high a value of $x_{\text {initial }}$ is to be used. However, operating at higher temperatures may cause other design problems such as excessive heat loss from the hydride, and the use of too high a value of $x_{\text {initial }}$ may risk hydride degradation because the hydride particles may break up. Therefore, the design of the hydride component must be made judiciously. If the hydride is likely to be significantly contaminated by gases evolved from the internal components of the $\mathrm{VCl}$ during its operation, then a larger quantity of hydride will be required because hydrogen absorption capacity will be lost due to this contamination.

\section{FABRICATION OF A BENCH-SCALE VCI TEST PANEL}

A flat panel of $\mathrm{VCl}$ was fabricated from stainlesssteel sheet and ceramic internal supports. The overall dimensions were $0.45 \mathrm{~m} \times 0.45 \mathrm{~m} \times 0.02 \mathrm{~m}$. The perimeter was permanently sealed by laser welding a band of $0.025 \mathrm{~mm}$ thick 304 stainless steel foil around the panel to seal the top and bottom sheets. As a part of this sealing process, the thin foil was also laser welded to itself. The internal zirconia ceramic supports were held in place in interference fit holes milled into 0.6 - $\mathrm{mm}$-thick aluminum sheets. The internal supports were separated from one another by a distance of $80 \mathrm{~mm}$ on a hexagonal pattern, and two layers of supports were used to decrease the thermal conductance through them. A 0.6 -mm-thick stainless-steel sheet separated the layers of ceramic supports. The steel and aluminum sheets serve as effective thermal radiation barriers; but two additional 0.025-mm-thick copper foils were added to further decrease the radiative heat transfer.

Two small, standard, copper-gasketed vacuum flanges were installed on the top surface of the panel. One of the flanges was used to attach the metal hydride and the other was used as the evacuation port. The metal hydride was a commercial unit-a cylindrical, porous steel capsule containing about $100 \mathrm{mg}$ of hydride and with an integral electrical heater [7]. The hydride was connected to an electrical feedthrough which included thermocouple leads as well as power-leads. A $0.075-\mathrm{mm}$-thick thermocouple was welded to the hydride to monitor its temperature during operation. Once the panel was evacuated and baked out at $200^{\circ} \mathrm{C}$ to remove adsorbed gasses, it was permanently sealed by pinching off the copper tube used for evacuation.

The thermal conductance through the thickness of the test $\mathrm{VCl}$ panel was measured using semiconductor heat flux gages that were calibrated against Natinal Institute of Standards and Testing standard reference material 1449 [8]. The panel was placed on a uniformly heated surface and was insulated around the perimeter to prevent convective heat loss from the sides. The two 2-cm-diameter flux gages were placed near the center of the top surface along with a surface thermocouple. The thermal conductance was calculated as the measured heat flux $\left(\mathrm{W} / \mathrm{m}^{2}\right)$ divided by the temperature difference between the top and bottom surfaces.

Figure 3 shows one cycle of operation of the $\mathrm{VCl}$ panel. While the temperature of the hydride changes very rapidly, the thermal conductance through the panel changes much more slowly because of the thermal inertia of the panel. The apparent thermal conductance of the panel during the transient portion of the recording is not likely to be accurate, however the nearly steady-state values of 9.0 and 1.0 are reproducible and accurate within the calibration uncertainty of the flux gages (about $\pm 5 \%$ ) for a given range of hydride temperatures.

The cyclic reproducibility of the hydride hydrogen source was tested by repeatedly cycling the direct current through the hydride heater at fixed peak amperage (about $4.5 \mathrm{~A}$ at $2.5 \mathrm{~V}$ ). This produces a hydride temperature range from about $75^{\circ} \mathrm{C}$ to about $500^{\circ} \mathrm{C}$ over a six-minute cycle more than 1200 times before the integral hydride heater failed. Periodic repeat measurements of the change in thermal conductance of the panel (on a much slower cycle) showed that its behavior was reproducible 


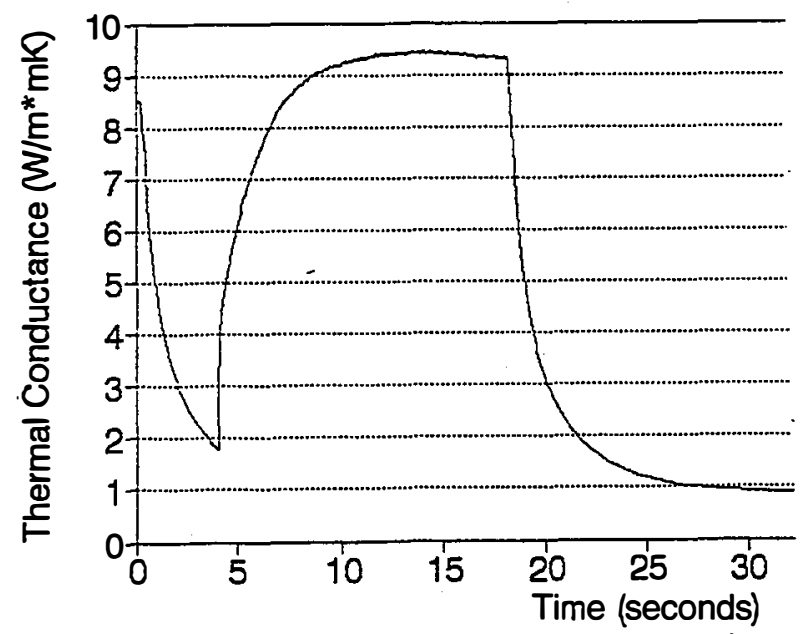

(Thousands)

Figure 3. Measured thermal conductance through VCI panel during a cycle of operation.

within a range of about $\pm 10 \%$, a variation which could be attributed to the variation in the range of hydride temperatures.

\section{COMPARISON OF MEASURED AND CALCULATED VCI THERMAL CONDUCTANCES}

Without a significant pressure of hydrogen, the lowest value of the panel conductance is made up of solid-phase conductance through the array of internal supports, the conductance through the perimeter foil seal, plus the radiative heat transfer conductance. The perimeter foil seal contributes to the minimum panel conductance no more than the following:

$$
C_{\text {foil }}=\left.4^{*}\right|^{*} t^{*} k_{s s} /\left(\left.w^{*}\right|^{2}\right)=0.18 \mathrm{~W} / \mathrm{m}^{2} \mathrm{~K}
$$

where $I$ is the panel edge length, $t$ is the foil thickness, $\mathrm{k}_{\mathrm{SS}}$ is the thermal conductivity of the foil $(16.2 \mathrm{~W} / \mathrm{mK})$, and $w$ is the thickness of the panel spanned by the foil perim- . eter seal. The radiative heat transfer is effectively limited by the multiple layers of radiation shields. The majority of the minimum panel conductance is due to the internal array of supports.

The measured range of $\mathrm{VCl}$ conductances is consistent with the expected range in hydrogen gas conductances (Fig. 1). Adding the minimum panel conductance of $1.0 \mathrm{~W} / \mathrm{m}^{2} \mathrm{~K}$ (fully evacuated with a cool hydride) to the calculated hydrogen gas conductance of about $8.4 \mathrm{~W} / \mathrm{m}^{2} \mathrm{~K}$ at pressures above 1 torr gives $9.4 \mathrm{~W} / \mathrm{m}^{2} \mathrm{~K}$ compared with the measured maximum panel conductance of $9.6 \mathrm{~W} / \mathrm{m}^{2} \mathrm{~K}$. The agreement is well within the uncertainty of the measurements.

\section{SOME POSSIBLE APPLICATIONS FOR VCI}

A variable-conductance vacuum insulation may be applicable wherever the requirements for insulation vary over time and heat transfer should be controlled electron- ically. Some possible applications in automobiles may include protecting lead-acid batteries against excessive underhood temperatures and thermally managing "hot" batteries.

\section{VCI MANUFACTURING ISSUES}

Several issues remain to be resolved before practical $\mathrm{VCl}$ enclosures can be fabricated. These include the choice construction materials, the durability of the hydrogen source, and the welding of the low-thermalconductance edge seals required in most $\mathrm{VCl}$ designs.

The materials used in the - $\mathrm{VCl}$ bench-scale demonstration were much too heavy to be practical. However, much lighter-weight vacuum insulation structures have been fabricated using laser-welded 0.2-mm-thick stainless steel envelopes and lighter-weight internal supports [9] demonstrating that such structures should be possible for $\mathrm{VCl}$ as well.

Although metal-hydride hydrogen sources are commercially available, they have not been designed to sustain a large number of repeated uses and further development of more durable sources is required. Nor is it clear that these hydrogen sources will not fail prematurely as a result of contamination from gases evolved from the surfaces and from within the volume of the materials of the $\mathrm{VCl}$ construction. More work is required to ensure the materials compatibility. It may even be necessary to use additional, separate reactive metal getter material in addition to the metal hydride hydrogen source to selectively trap the potentially contaminating gasses.

Perhaps the most difficult manufacturability problem is the design of the thin-foil, low-thermal-conductance edge seals which will be required for most $\mathrm{VCl}$ enclosure designs. We have shown that a very thin stainless-steel foil can be laser welded to form a vacuum-tight perimeter seal. This welding required extreme care in the fixturing and will require further development before it is practical for a mass-production process. A vacuum furnace brazing operation has also been used successfully with somewhat thicker $(0.075 \mathrm{~mm})$ stainless-steel foil and may be a more forgiving process. Further work is required.

\section{SUMMARY AND CONCLUSIONS}

A design for a variable-conductance vacuum insulation has been described and demonstrated to function as predicted in a bench-scale prototype panel of $\mathrm{VCl}$. The use of hydrogen gas to provide controlled thermal conductance through such an insulation whenever and to the extent needed appears to be feasible from these calculations and experiments.

The upper limit to the thermal conductivity of the $\mathrm{VCl}$ is provided by the hydrogen gas and is limited to about $0.17 \mathrm{~W} / \mathrm{mK}$; the lower limit to the effective thermal conductivity of the vacuum insulation (with hydrogen reabsorbed into the metal hydride dispenser) is determined by the details of the insulation design, such as the thickness of the insulation, the perimeter-to-area 
conductivity of the vacuum insulation (with hydrogen reabsorbed into the metal hydride dispenser) is determined by the details of the insulation design, such as the thickness of the insulation, the perimeter-to-area ratio, thickness of the perimeter seal, and the number and geometry of the internal supports and radiation shields. Designs of $\mathrm{VCl}$ with a dynamic range (the ratio of maximum conductance to minimum conductance) that is much higher than reported here, appears to be possible.

The $\mathrm{VCl}$ appears to have potential applicability wherever the management of heat flow into and out of an insulated enclosure is required. Some applications in automobiles were suggested. The application of $\mathrm{VCl}$ to the thermal management of automobile "hot" batteries is presently under development at NREL.

\section{ACKNOWLEDGEMENTS}

This work was supported by the U.S. Department of Energy under contract No. DE-AC02-83CH10093.

\section{NOMENCLATURE}

A area (m)

NA Avagadro's number (number of molecules per mole) $=6.022 * 10^{23}$

$C_{p}$ specific heat at constant pressure $=$ $14309\left(\mathrm{~J} /\right.$ mole K) for $\mathrm{H}_{2}$

Cv specific heat at constant volume $=$ $10201\left(\mathrm{~J} /\right.$ mole $\mathrm{K}$ ) for $\mathrm{H}_{2}$

$\mathrm{d}_{0}$ molecular diameter $=.274^{\star} 10^{-9}(\mathrm{~m})$ for hydrogen

$\mathbf{F}_{\mathrm{zr}} \quad$ weight fraction of hydride which is zirconium (dimensionless)

k Boltzmann's constant $=1.380^{*} 10^{-23} \mathrm{~J} / \mathrm{K}$ or $8.616^{\star} 10^{-5}$ eV/atom K

$\mathbf{k}_{\mathrm{ss}} \quad$ thermal conductivity of the edge foil seal (16.2 W/mK)

I $\mathrm{VCl}$ panel edge length $(\mathrm{m})$

m molecular mass $=0.335^{\star} 10^{-23} \mathrm{~g}$ for $\mathrm{H}_{2}$

$\mathrm{mfp}$ mean-free path length of gas molecule $(\mathrm{m})$

$\mathbf{M W}_{\mathrm{H} 2}$ molecular weight of hydrogen $(2.016 \mathrm{~g} / \mathrm{mole})$

$\mathrm{MW}_{\mathrm{zr}}$ molecular weight of zirconium (91.22 $\left.\mathrm{g} / \mathrm{mole}\right)$

$n$ number density of gas molecules $(m-3)$

$\mathbf{n}_{\mathrm{c}} \quad$ critical concentration of hydrogen gas molecules. $\left(\mathrm{m}^{-3}\right)$

$P_{0} \quad$ parameter in Sievert's equation (13) in units of $\mathrm{Pa}$

$\mathbf{P}_{c} \quad$ critical pressure of hydrogen $(\mathrm{Pa})$

R molar gas constant $=8.3145(\mathrm{~J} /$ mole $\mathrm{K})$

$t$ edge foil thickness (m)
$\mathbf{T} \quad$ gas temperature (K)

$T_{a} \quad$ hydride alloy operating temperature $(K)$

$T_{i} \quad$ initial gas molecule temperature $(K)$

$T_{r} \quad$ gas molecule temperature after rebounding from a surface $(K)$

$\mathbf{T}_{\mathrm{s}} \quad$ surface temperature $(\mathrm{K})$

w thickness of $\mathrm{VCl}$ panel $(\mathrm{m})$

z thickness of gas-filled gap between warm and cold surfaces $(\mathrm{m})$

$\alpha_{n} \quad$ accommodation coefficient of a gas/surface ${ }_{n}$

$\gamma$ the ratio of specific heats, $C_{p} / C_{v}=1.4$ for $\mathrm{H}_{2}$

$\mathrm{K}$ free-molecular conductivity of a gas

$\eta \quad$ gas viscosity (Pa-s)

\section{REFERENCES}

1. O'Hanlon, J.F., A User's Guide to Vacuum Technology, John Wiley and Sons, New York, NY, 1980.

2. Handbook of Chemistry and Physics, 58 ed., Weast, R.C. Ed., CRC Press, West Palm Beach, FL, 1977.

3. Wachman, H.Y., "The Thermal Accommodation Coefficient: A Critical Survey," Am. Rocket Soc. J., 32 (\#1), p 2-12, 1962.

4. Thermophysical Properties of Matter, Volume 3, Thermal Conductivity: Nonmetallic Liquids and Gases, Y.S. Touloukian, et al. eds., Plenum Press, New York, NY, 1970.

5. Libowitz, G.G., "Condensed Phase Metal-hydrogen Systems and Their Role in Controlled Fusion Reactors," in The Chemistry of Fusion Technology, D.M. Gruen ed., Plenum Press, New York, NY, pp. 321-337, 1975.

6. Boffito, C. et al., "A Nonevaporable Low Temperature Activatable Getter," J. Vac. Sci. Technol., 18 (\#3), pp. 11.17-1120, 1981.

7. Ergenics, Inc., Ringwood, NJ 07456, 1992.

8. Smith, D.R., "Microporous Fumed-Silica Insulation as a Standard Reference Material of Thermal Resistance at High Temperature," NISTIR 89-3919, 1989.

9. Benson, D.K., "Compact Vacuum Insulation-A New Flat Rolled Steel Product," Proceedings of the 1991 Mechanical Working and Steel Processing Conference, October, 1991. 